\title{
CARBONIZAÇÃO CONTÍNUA: SIMULAÇÃO DO CONSUMO DE CARVÃO VEGETAL NO ALTO-FORNO 1 DA VALLOUREC TUBOS DO BRASIL*
}

\author{
Rosiane Mary Rezende Faleiro ${ }^{1}$ \\ Ronaldo Santos Sampaio ${ }^{2}$ \\ Cláudio Musso Velloso ${ }^{3}$ \\ Flávio Roberto Silva de Azevedo 4 \\ Fernando Lopes Latorre ${ }^{5}$
}

\section{Resumo}

A Vallourec tem investido na tecnologia de carbonização contínua com objetivo de produzir carvão vegetal, $\mathrm{CV}$, de boa qualidade siderúrgica e maior rendimento na conversão madeira / CV siderúrgico, tornando o processo viável em termos técnicos e econômicos para o cenário brasileiro. O objetivo desse trabalho foi comparar, por simulação termoquímica, o impacto relativo nos consumos de CV granulado enfornado pelo topo, utilizando CV produzido por fornos retangulares de alvenaria e CV obtido no reator de carbonização contínua da Vallourec, o Carboval. A qualidade siderúrgica superior do CV Carboval permitiu reduzir o consumo específico de CV granulado em 18,2kg/t que, somando ao melhor rendimento gravimétrico e menor geração de frações finas, torna atrativa e viável esta tecnologia. Estas vantagens impulsionam o setor a sair do artesanal para o industrial na produção de CV.

Palavras-chave: Carbonização contínua; Carvão vegetal; Modelo termoquímico.

\section{CONTINUOUS CARBONIZATION: CHARCOAL CONSUMPTION SIMULATION OF VALLOUREC TUBOS DO BRASIL BLAST FURNACE 1}

\begin{abstract}
Vallourec has invested in continuous carbonization technology in order to produce charcoal with good quality and higher conversion wood to charcoal, making the process feasible in technical and economic terms for the Brazilian scenario. The goal of this study was to compare, by thermochemical simulation, the impact on the specific consumption of the granular charcoal fed to the top of the blast furnace, using the charcoal from the traditional masonry kilns and the charcoal produced by the continuous carbonization reactor of Vallourec, the Carboval. The top steel quality of Carboval charcoal allowed to reduce the specific consumption of granular charcoal fed to the top in $18.2 \mathrm{~kg} / \mathrm{t}$ that, adding to higher gravimetric yield and less generation of the fine fractions, makes it attractive and feasible this technology. These advantages drive the industry out of the artisanal to the industrial production of charcoal.
\end{abstract}

Keywords: Continuous carbonization; Charcoal; Thermochemical model.

1 Bacharel e Mestre em Estatística, Doutora em Engenharia Metalúrgica, Coordenadora Técnica, Superintendência de Siderurgia, Vallourec Tubos do Brasil, Belo Horizonte, Minas Gerais, Brasil.

2 Graduado, Mestre e Doutor em Engenharia Metalúrgica, Especialista em Engenharia Econômica, Diretor Presidente, RSConsultants Ltda., Belo Horizonte, Minas Gerais, Brasil.

3 Graduado e Mestre em Engenharia Metalúrgica, Superintendente, Superintendência de Siderurgia, Vallourec Tubos do Brasil, Belo Horizonte, Minas Gerais, Brasil.

4 Graduado e Mestre em Engenharia Metalúrgica, Dr. Ing., Chief Inovation Officer, Vallourec, Paris, França.

5 Engenheiro Metalúrgico, Gerente, Gerência do Projeto de Carbonização Contínua, Vallourec Florestal, Paraopeba, Minas Gerais, Brasil. 


\section{INTRODUÇÃO}

A transformação da madeira em carvão vegetal (CV), carbonização, ponto de conexão entre a floresta e o alto-forno, tem como função concentrar energia da madeira em partículas, CV granulado para uso como termorredutor nos altos-fornos. $\mathrm{Na}$ carbonização, a madeira é aquecida com gases provenientes de sua própria combustão parcial para atender às necessidades de remoção parcial dos materiais voláteis, ricos em água, oxigênio e compostos orgânicos leves e oleosos. O produto resultante é o CV rico em carbono (SAMPAIO, 2008).

A conversão da madeira em CV, com um definido teor de carbono fixo, é o índice técnico utilizado para avaliar a eficiência do processo de carbonização. Ele é denominado Rendimento Gravimétrico, $\boldsymbol{R}_{\boldsymbol{g}}$, conforme ilustrado na Equação 1:

$$
R_{g}=\frac{\text { Peso seco de CV produzido }}{\text { Peso de madeira seca utilizada }} * 100
$$

O rendimento gravimétrico e a qualidade do CV são influenciados pelas propriedades da madeira (densidade aparente, teor de lignina, estrutura fibrosa, etc.) que resultarão na qualidade final do $\mathrm{CV}$. Os processos de carbonização influenciam na eficiência da conversão e na qualidade siderúrgica resultante do $\mathrm{CV}$, em especial a fração de finos gerados, não possíveis de serem carregadas pelo topo dos altosfornos.

O CV pode ser produzido por vários processos (PINHEIRO, 2008). Os fornos de alvenaria, incluindo os retangulares, são os mais comuns no Brasil. Por serem reatores artesanais apresentam baixos rendimentos gravimétricos (entre 28 a 35\%) e elevadas variabilidades nos parâmetros físicos e químicos do CV produzido. A matéria volátil não utilizada é perdida para o meio ambiente.

Com isso, observa-se maior interesse em estudos a respeito do aproveitamento dos gases da carbonização através da sua combustão, buscando a melhoria do ambiente de trabalho e a obtenção de energia térmica para sua utilização na secagem de lenha, ou mesmo para produção de energia elétrica. Contudo, para que estas tecnologias sejam implantadas pelos produtores de CV, elas devem ser eficientes e, principalmente, de baixo custo (CARNEIRO, 2012). Devido à elevada heterogeneidade e baixo poder calorífico do material volátil, não é viável sua utilização para termogeração.

O foco deste trabalho está na simulação dos benefícios da qualidade siderúrgica do CV do processo de carbonização contínua, reator industrial que consegue atender, rigorosamente, os níveis térmicos necessários no interior do reator, para se chegar ao mais homogêneo e melhor CV siderúrgico possível para um desejado teor de carbono fixo como o CV proveniente dos tradicionais fornos cerâmicos artesanais de carbonização.

O reator de carbonização contínua utilizado para a fabricação do CV siderúrgico tem origem em tecnologia francesa adquirida pela Vallourec Tubos do Brasil, VBR. O forno Carboval foi instalado em Paraopeba, MG, e inaugurado em abril de 2008 (Figura 1). Possui capacidade de produção no reator de 7.500 t/ano e inclui o sistema de picagem de madeira para toretes, o secador de toretes e, seguido do forno contínuo, o resfriamento secundário e silo de despacho de $\mathrm{CV}$ granulado. Os valores típicos obtidos de rendimento gravimétrico são da ordem de 40\% com $74 \%$ de carbono fixo e no máximo $1 \%$ de cinzas quando não contaminado por terra do 
solo, conforme desenvolvimentos e testes realizados na planta piloto em Paraopeba, MG (média anual de 2013 a 2015).

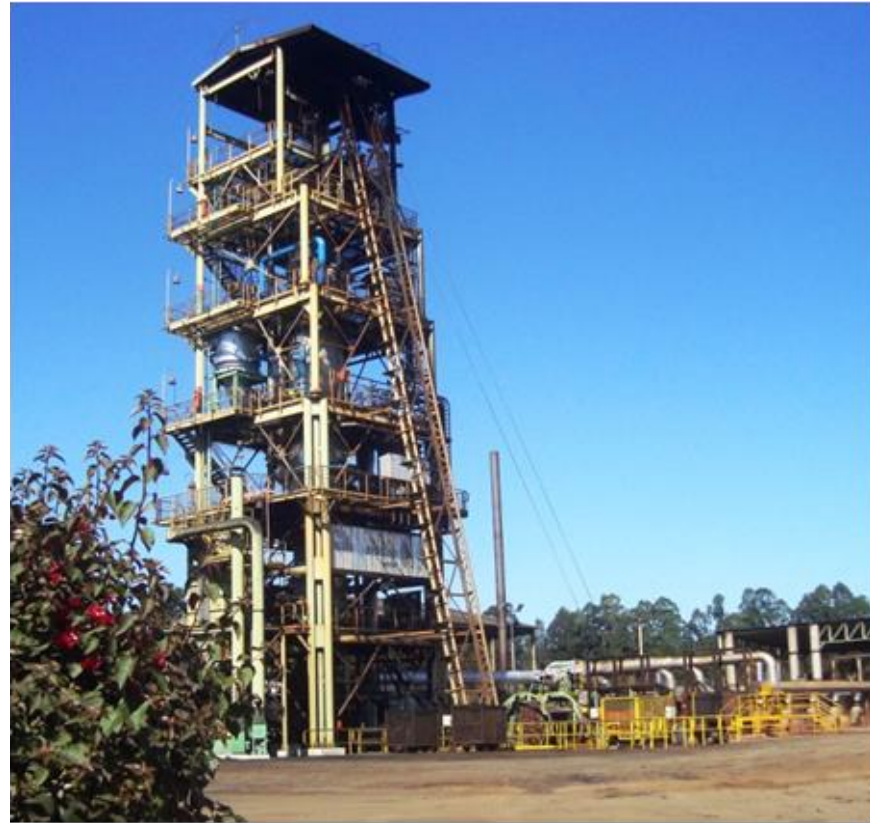

Figura 1. Reator de carbonização contínua Carboval

A Vallourec tem investido e esforçado para adaptar tecnologia às suas madeiras e tornar viável em termos técnicos e econômicos para o cenário brasileiro. Como resultado, dispõe do necessário para garantir o sucesso técnico, o domínio de engenharia, somados das vantagens econômica, ambiental e social do empreendimento.

O recurso escasso para os altos-fornos a CV é o carvão granulado enfornado pelo topo, conhecido como carvão de topo. No caso da VBR, o carvão de topo é o carvão com granulometria acima de $10 \mathrm{~mm}$. O tamanho da floresta necessária para este carvão de topo vai depender, além do rendimento gravimétrico, da fração de carvão que consegue chegar ao topo dos altos-fornos acima de $10 \mathrm{~mm}$ vindas das unidades de carbonização. Na VBR, a \% de carvão de topo está na ordem de $71 \%$ para 0 carvão produzido por fornos retangulares. Logo, a madeira necessária da floresta plantada pode ser inferida pela Equação 2 abaixo, resultante da Equação 1:

$$
\text { Peso de madeira seca }\left(\frac{k g}{t}\right)=\frac{P_{c v} \text { de topo }\left(\frac{k g}{t}\right)}{R_{g}} * \frac{100}{\% \text { carvão de topo }}
$$

Como o carvão produzido pelo forno Carboval possui maior rendimento gravimétrico e maior \% de carvão de topo, já que não há geração de tiço e a geração de finos é menor, necessita de menor quantidade de madeira, ou seja, menor tamanho de floresta.

O objetivo desse trabalho foi simular, utilizando um modelo termoquímico, as diferenças entre os consumos médios reais de carvão de topo do alto-forno a CV produzido por fornos retangulares (Figura 2), e o correspondente com a melhor qualidade do CV produzido pelo reator Carboval (Figura 1- carbonização contínua) a partir dos valores químicos e físicos dos mesmos obtidos na produção no reator Carboval com exatamente a mesma madeira. 


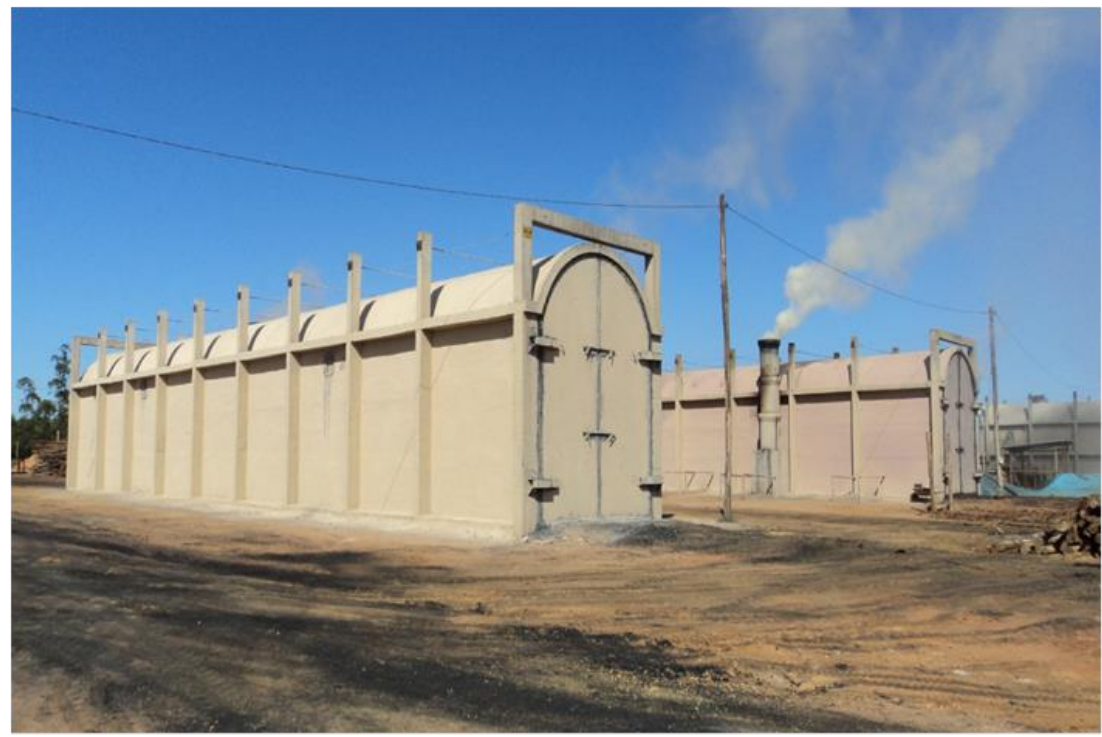

Figura 2. Fornos retangulares artesanais de alvenaria.

\section{MATERIAIS E MÉTODOS}

O software estatístico MINITAB foi utilizado para a elaboração dos gráficos e a realização dos testes estatísticos. O teste $t$ foi utilizado para comparar as médias (TRIOLA, 1999). O nível de significância considerado foi de 5\%.

Utilizou-se o modelo termoquímico Optimum (macros no Excel), desenvolvido pelas empresas VBR e RSConsultants, o qual simula cenários de produção e operação para altos-fornos a CV.

No modelo termoquímico, parte-se da base do mesmo estar representando o AltoForno 1 da VBR com os valores médios reais de 2015 para o CV produzido por fornos retangulares. São mantidas as eficiências termoquímicas (rendimento gasoso), a carga metálica, a taxa de injeção, a qualidade e a temperatura do gusa. $\mathrm{Na}$ simulação, variam-se apenas os resultados das análises imediatas do CV de topo e do CV injetado, entrando com os valores reais de qualidade do CV Carboval de 2015.

A Figura 3 ilustra os únicos parâmetros que foram modificados na simulação, que são as análises imediatas do CV carregado pelo topo e do pó de CV injetado. 


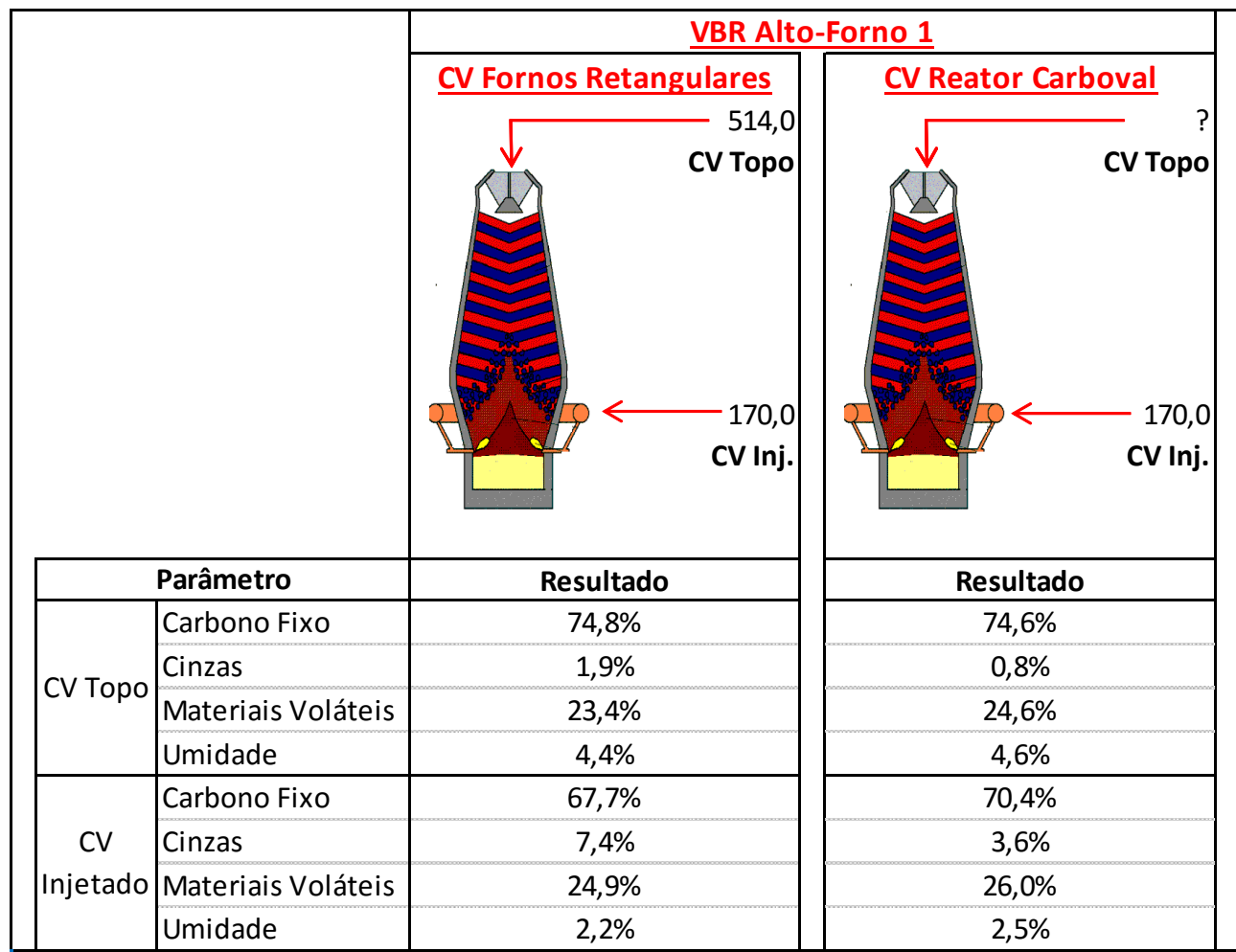

Figura 3. Resultados de qualidade do CV utilizado no modelo Optimum.

\section{RESULTADOS E DISCUSSÃO}

Exemplo de CV produzido pelo reator Carboval pode ser visualizado pela Figura 4. Em seguida, são mostrados os resultados de qualidade dos carvões produzidos em fornos retangulares e Carboval recebidos na VBR em 2015. Observa-se visualmente uma uma maior variabilidade nos resultados da Carboval devido ao número de amostras (10) ser bem menor do que dos fornos retangulares (1804).

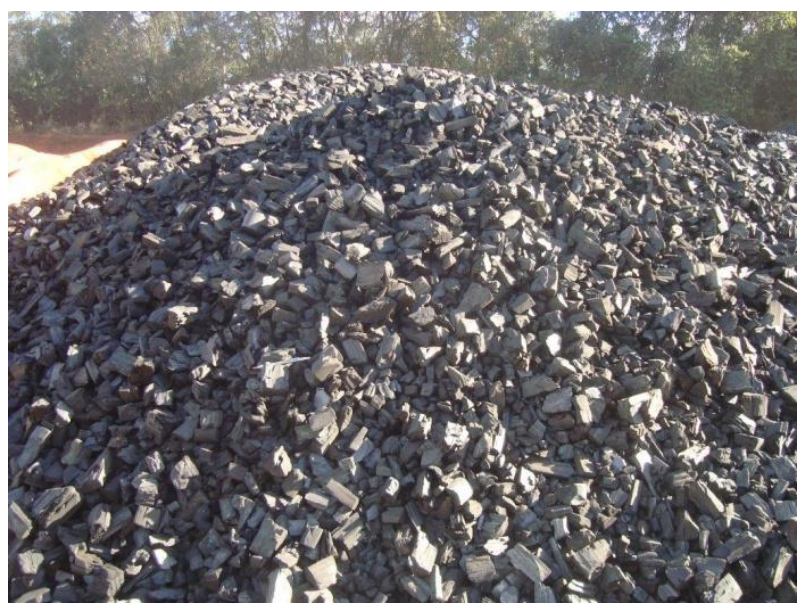

Figura 4. Exemplo de CV produzido pelo reator Carboval.

Na Figura 5 pode-se ver que o CV Carboval possui maior teor médio de carbono fixo do que o CV de fornos retangulares (valor- $p=0,000$ ). 


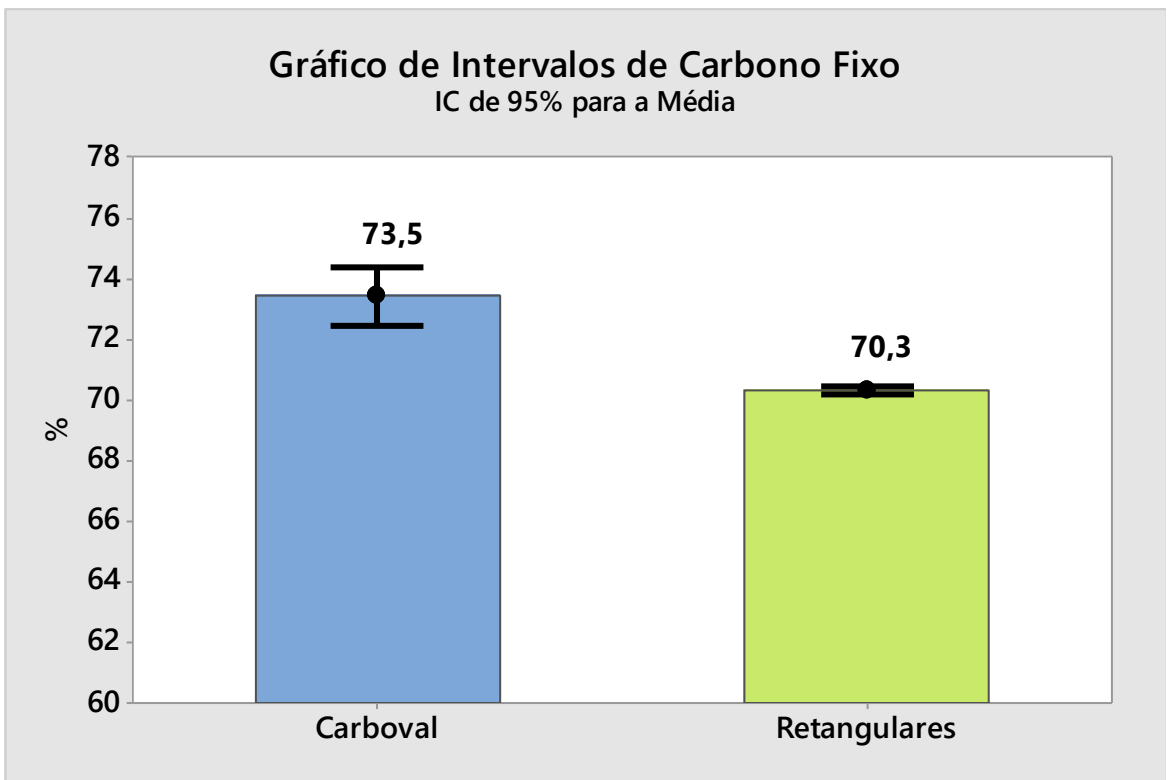

Figura 5. Resultados de carbono fixo por tipo de forno.

Existe diferença significativa entre as médias dos teores de cinzas dos carvões. Como mostra a Figura 6, o CV Carboval apresenta menor teor médio de cinzas (valor-p $=0,000)$. Ressalta-se que os resultados de qualidade do CV Carboval referem-se a carvão foi estocado e manuseado em solo terroso, por isso o teor de cinzas superou o valor máximo esperado de $1 \%$.

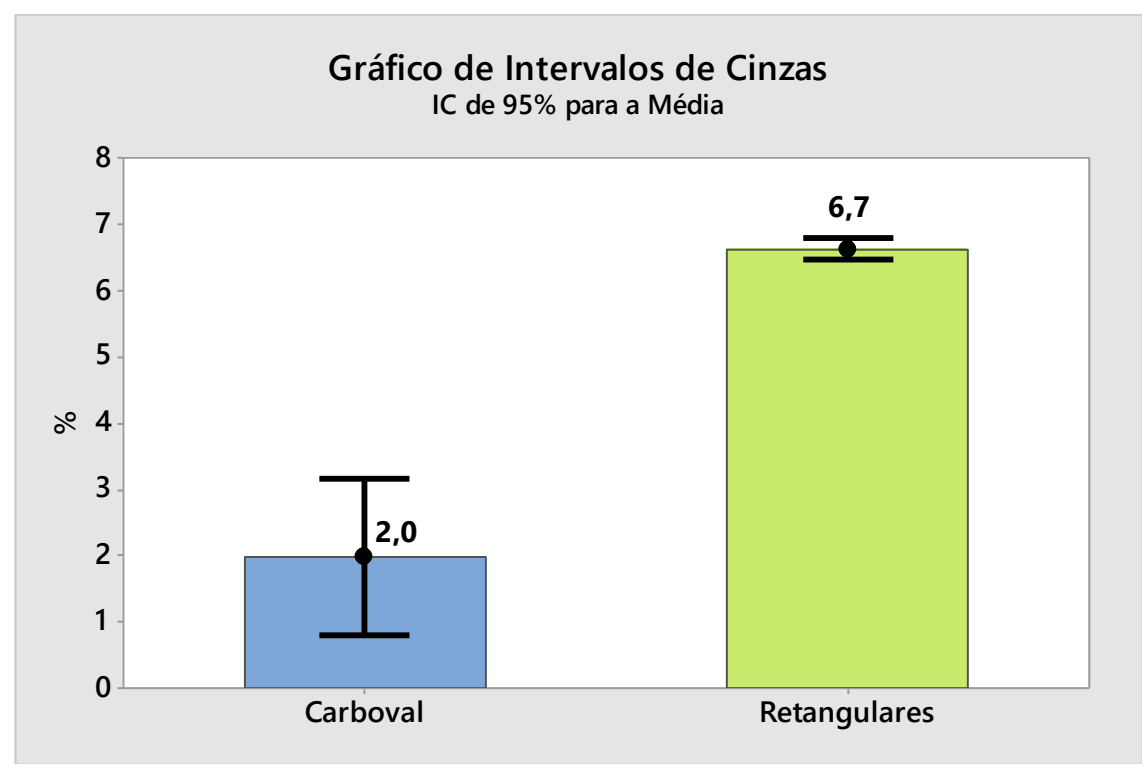

Figura 6. Resultados de cinzas por tipo de forno.

Pela Figura 7 também pode-se ver que houve diferença entre os teores médios de materiais voláteis (valor- $p=0,001$ ), sendo este maior para o CV produzido pelo reator Carboval, o que favorece a redução indireta da carga metálica favorecendo a redução do consumo de $\mathrm{CV}$. 
Gráfico de Intervalos de Materiais Voláteis IC de $95 \%$ para a Média

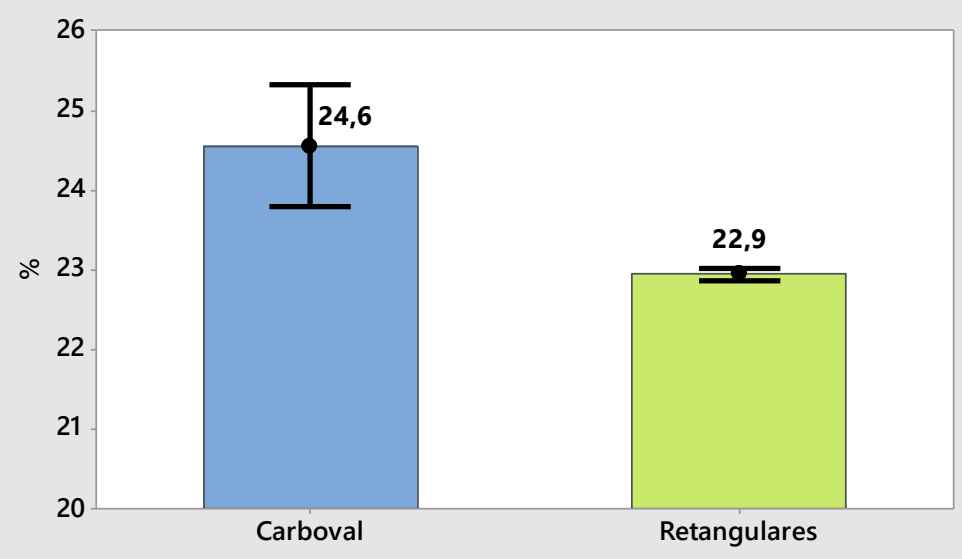

Figura 7. Resultados de materiais voláteis por tipo de forno.

Não houve diferença entre os teores médios de umidade (valor-p $=0,443$ ) e tamanho médio (valor-p $=0,369$ ), mostrados nas Figuras 8 e 9, respectivamente. Vale ressaltar que e o CV Carboval precisou passar pelos mesmos caminhos dos fornos artesanais, ou seja, foi colocado no caminhão, removido do caminhão e colocado no solo terroso e depois removido com pás carregadeira para dentro do caminhão, gerando boa quantidade de finos e se contaminando com terra, apresentando então, tamanho médio semelhante ao dos fornos retangulares.

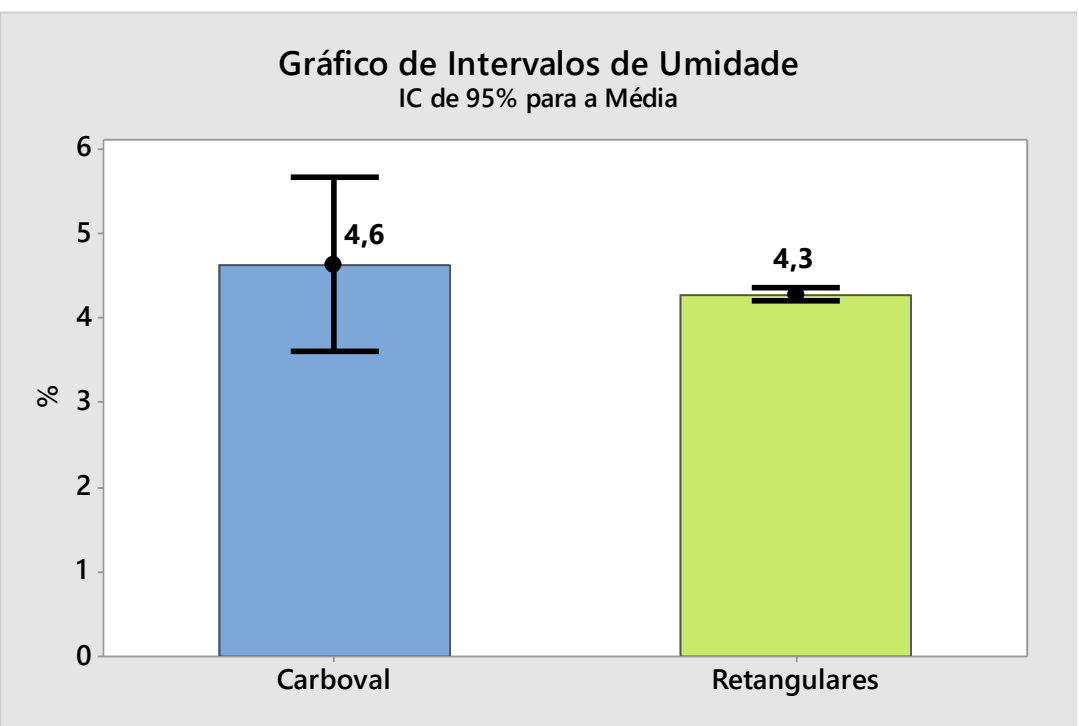

Figura 8. Resultados de umidade por tipo de forno. 
Gráfico de Intervalos de TM

IC de $95 \%$ para a Média

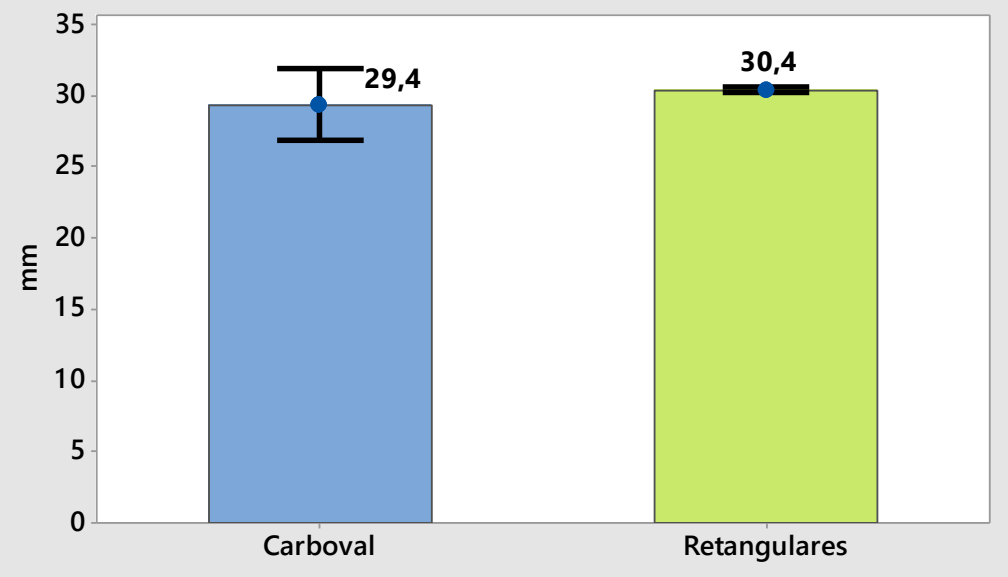

Figura 9. Resultados de tamanho médio por tipo de forno.

O CV Carboval possui média bem menor de finos (fração menor do que $10 \mathrm{~mm}$ ) do que 0 CV produzido por fornos retangulares (valor-p $=0,000$ ), como pode ser visualizado na Figura 10.

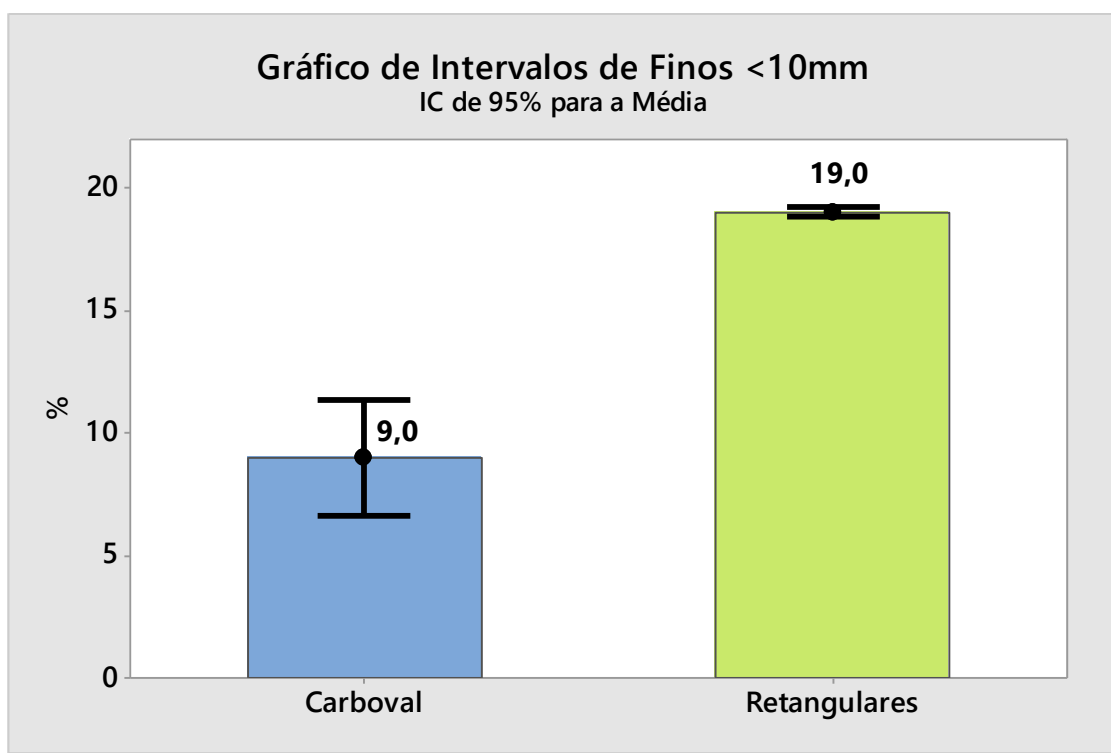

Figura 10. Resultados de finos $<10 \mathrm{~mm}$ por tipo de forno.

Não houve diferença na densidade média entre os carvões produzidos pelos dois diferentes fornos como mostra a Figura 11 (valor- $p=0,499$ ). 


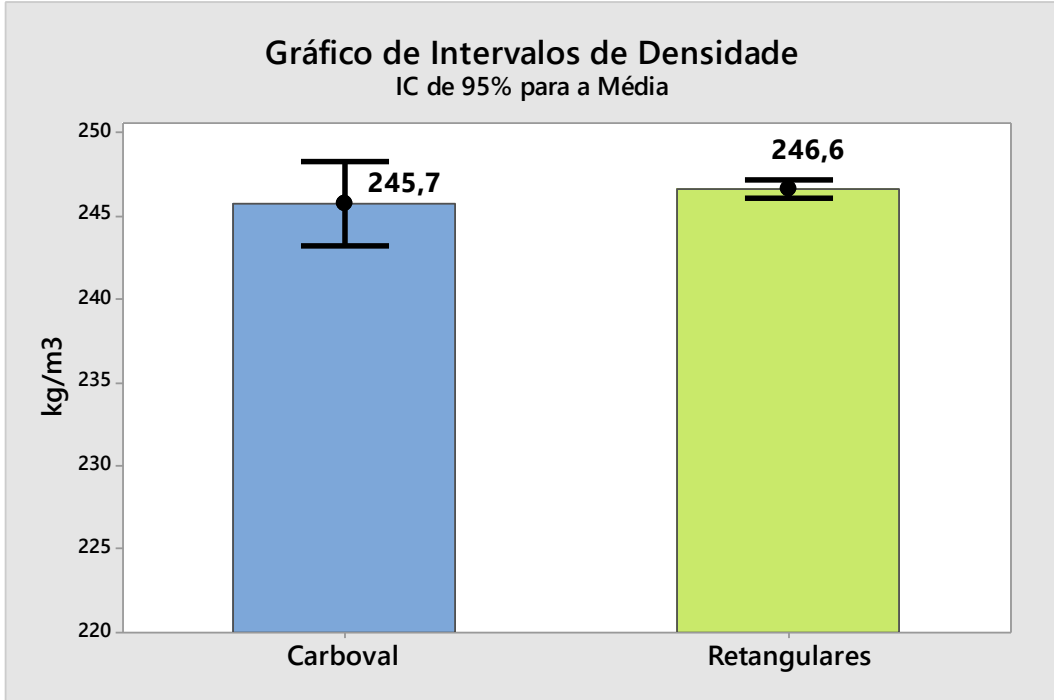

Figura 11. Densidade a granel por tipo de forno.

O próximo passo do trabalho foi a simulação, considerando carga metálica do altoforno com $70 \%$ de pelota e $30 \%$ de minério, taxa de injeção de $170 \mathrm{~kg} / \mathrm{t}$ e as médias dos parâmetros operacionais reais de 2015.

Utilizando os resultados de qualidade do CV após peneiramento na usina, mostrados na Figura 3, o consumo de carvão de topo da base foi de 514,0kg/t. Simulando com a qualidade do CV de topo de CV injetado do CV produzido pelo reator Carboval, o consumo de carvão de topo simulado foi de $495,8 \mathrm{~kg} / \mathrm{t}$, ou seja, $18,2 \mathrm{~kg} / \mathrm{t}$ a menos; redução de $3,5 \%$ da quantidade de carvão (Figura 12).

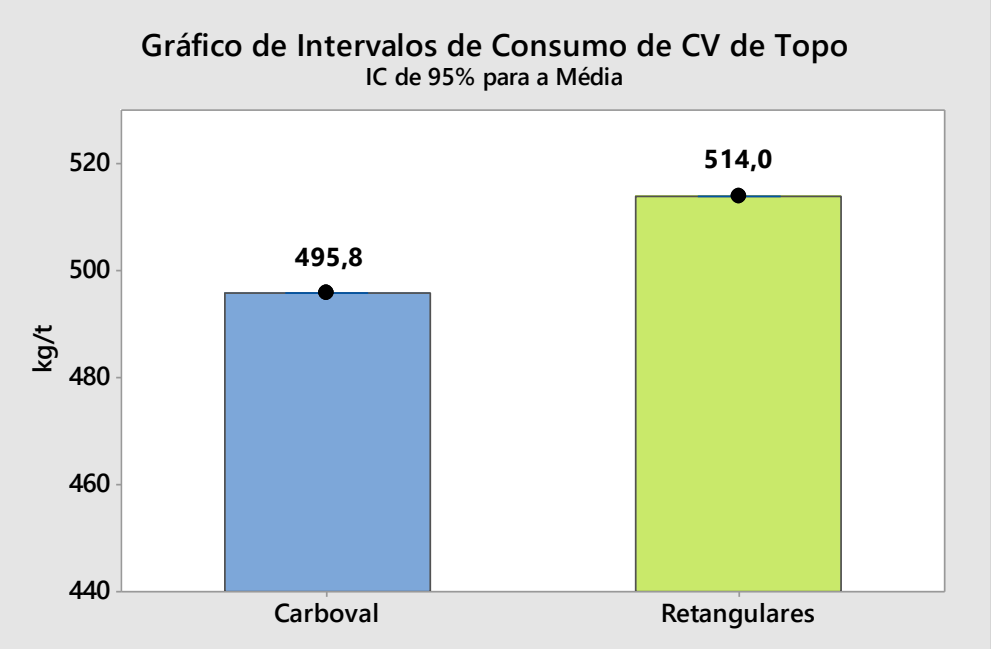

Figura 12. Resultados da simulação de consumo de carvão de topo por tipo de forno.

Considerando que o CV de fornos retangulares possui em média $71 \%$ de $\mathrm{CV}$ de topo e $32 \%$ de rendimento gravimétrico, e que para o CV Carboval esses valores são de $85 \%$ e $40 \%$, os consumos de CV bruto são de $724 \mathrm{~kg} / \mathrm{t}$ (Retangulares) e $583 \mathrm{~kg} / \mathrm{t}$ (Carboval). Dessa forma, a utilização de CV Carboval permite uma redução de $141 \mathrm{~kg} / \mathrm{t}$, que é uma economia de CV de $19,5 \%$. 


\section{CONCLUSÃO}

A tecnologia empregada no processo de carbonização é um dos fatores que influenciam no rendimento gravimétrico e na qualidade do CV.

O CV produzido por carbonização contínua possui maior rendimento gravimétrico (na ordem de $40 \%$ ) do que os fornos de alvenaria (28 a $35 \%$ ), além de emitir menor quantidade de gases poluentes na atmosfera, os quais geram passivos ambientais $e$ perda de energia.

A carbonização contínua é a tecnologia mais avançada, com maior eficiência no fechamento do balanço de massas, energia e homogeneidade do CV produzido.

A Vallourec tem investido na tecnologia de carbonização contínua com objetivo de produzir CV de alta qualidade e maior rendimento gravimétrico, e tornar o processo viável em termos técnicos e econômicos para o cenário brasileiro.

O CV Carboval apresentou melhores resultados de análises química e física (maior teor médio de carbono fixo, e menor teor médio de cinzas, maior teor médio de materiais voláteis, menor porcentagem média de finos), favorecendo a redução de consumo de CV no alto-forno.

Os parâmetros tamanho médio, umidade e densidade a granel não apresentaram diferenças significativas nas médias.

Com relação ao consumo de carvão de topo, o CV Carboval apresentou melhor desempenho, permitindo uma redução de $18,2 \mathrm{~kg} / \mathrm{t}$ em relação ao $\mathrm{CV}$ produzido por fornos retangulares (redução de $3,5 \%$ da quantidade de carvão de topo). Em termos de CV bruto, representa uma redução de $141 \mathrm{~kg} / \mathrm{t}(19,5 \%)$.

\section{REFERÊNCIAS}

1 SAMPAIO, R. S. Estudo Prospectivo do Setor Siderúrgico. NT Conversão da Biomassa em Carvão Vegetal Situação Atual. CGEE: Ciência, Tecnologia e Inovação. 2008, Belo Horizonte.

2 PINHEIRO, P. C. C. ; SAMPAIO, R. S. ; REZENDE, M. E. A. . A produção de Carvão Vegetal: Teoria e Prática II. ,2008.

3 CARNEIRO, A. C. et. al. Estudo da Viabilidade Técnica e Econômica da Produção de Carvão Vegetal em Fornos Circulares com Baixa Emissão de Poluentes. EPEA/ESALQ

4 Viçosa, 2012 (CNA Brasil)

5 TRIOLA, M. F. Introdução à Estatística. Sétima Edição. Livros Técnicos e Científicos. 1999, Rio de Janeiro. 